\title{
Eliminating Mother to Child Transmission of HIV in Arua District Through Mother-Baby-Pair Points
}

\author{
Eddy Ika ${ }^{1}$, Isaac Wonyima Okello ${ }^{2} \&$ Kizito Omona ${ }^{3}$ \\ ${ }^{1}$ Public Health Specialist and Environmental Health and Safety Officer, Uganda Martyrs Hospital Lubaga, \\ Kampala, Uganda \\ ${ }^{2}$ Assistant District Health Officer, Maternal Child Health/Nursing, Nwoya District Local Government, Uganda \\ ${ }^{3}$ Lecturer, Uganda Martyrs University, Faculty of Health Sciences, Kampala, Uganda \\ Correspondence: Dr Kizito Omona, Lecturer, Uganda Martyrs University, Faculty of Health Sciences. P. O. Box \\ 5498, Kampala, Uganda. Tel: 256-70-646-4873. E-mail: komona@umu.ac.ug
}

Received: March 8, 2021

doi:10.20849/ijsn.v6i2.867
Accepted: April 8, 2021

Online Published: June 30, 2021

URL: https://doi.org/10.20849/ijsn.v6i2.867

\begin{abstract}
Introduction: Mother-to-child transmission is the leading cause of HIV infection in children. Without treatment, half of these HIV infected children die before their second birthday.

Purpose: To establish the contribution of mother-baby-pair points approach to eMTCT outcomes in Arua District Uganda.

Material and Methods: A descriptive and analytical cross sectional study design which employed mixed methods approach was used. 196 HIV positive breast feeding mothers from three government hospitals (Arua Regional Referral Hospital, Adumi Health Center IV and Oli Health Center IV) were interviewed. Data was collected using structured questionnaires, focus group discussions and interviews guides.

Results: Majority $168(85.7 \%)$ of the respondents and their babies were enrolled to eMTCT care immediately after delivery and up to $17(8.7 \%$ ) were enrolled beyond two weeks after delivery. Reasons for enrolment into care included; counseling before, during and after pregnancy on the importance of adherence to ART, early enrolment into care and delivery in a health facility. Most of the babies enrolled in mother-baby-points were HIV sero-negative (75.5\%) with only $6.6 \%$ of them being sero-positive, thus signifying the contribution of mother-baby-points towards eliminating mother-child-transmission of HIV. Age of mothers was associated with retention on eMTCT care $\left(\chi_{(5)}^{2}=11.19, \mathrm{p}=0.048\right)$. Again, having had any form of education on eMTCT was associated with retention on eMTCT care $(\mathrm{p}=0.001)$.
\end{abstract}

Conclusion: The degree of enrollment in to eMTCT care was high but some mothers who still enrolled late. This affects early infant diagnosis, uptake of eMTCT services and retention of mothers and their infants.

Keywords: elimination of mother to child transmission (eMTCT), mother-baby-pairs, retention on care

\section{Introduction}

\subsection{Background of the Study}

Globally, 3.3 million children were living with HIV in 2012, with an estimated 260000 newly infected with HIV according to World Health Organization (WHO, 2014) and in this Mother-to-child transmission (MTCT) of HIV is an important contributor to the transmission. It is estimated that less than $15 \%$ of pregnant women get tested for HIV and less than $12 \%$ of sero-positive women have access to antiretroviral prophylaxis in many resource poor settings, including the simplest single dose regiment (WHO, 2014). The implication of this is that without the appropriate medical intervention and treatment, about 15-30\% of infants born to HIV-positive mothers will become infected with HIV during gestation and delivery, with a further 5-15\% becoming infected through breastfeeding (Sidik, 2014). Consequently, HIV infected infants become vulnerable to a life-long chronic condition that potentially shortens life expectancy and contributes to substantial human, social, and economic costs (Alonso, 2010).

In order to prevent the transmission of HIV from mother to child in Africa, World Health Organization (WHO, 2010) advocates for comprehensive approaches. This comprehensive approach entails: primary prevention of 
HIV infection among women of 15 - 49 years of age, an unwanted pregnancies among women living with HIV, preventing HIV transmission from a woman living with HIV to her infant and providing appropriate treatment, care and support to mothers living with HIV and their children and families (WHO, 2010)

Cognizant of the magnitude of this problem of MTCT of HIV, Uganda launched a program geared to words elimination of mother to child transmission (eMTCT) of HIV through mother baby pair point approach. This study therefore examined the contribution of mother-baby-pair point (from Ante natal care to post natal period) approach to eMTCT outcomes in Arua district.

Much as maternal mortality is a serious issue of concern, it should be noted that HIV positive mothers if not accorded skilled care are at higher risk of transmitting the virus to their unborn babies (Dabis, et al., 2000). This clearly raises the question of whether the maternal health or maternal health care is a mystery or reality. One of such maternal health issues of concern to this study is the issue of HIV/AIDS and particularly mother to child transmission. However before looking into it, it is important to understand what maternal health is all about.

Ideally maternal health care should include more than having mere access to a skilled healthcare professional, and states should be encouraged to go beyond providing only the four minimum standards stated above. One of the core maternal care issue facing the world today as noted earlier on is HIV especially mother to child transmission (UNAIDs, 2016).

Globally, the advance in antiretroviral therapy is on a Fast-Track route that surpassed HIV with its coverage reaching $46 \%$ (43-50\%) at the end of 2015 with high improvements in the most affected regions of eastern and southern Africa. The improvement from 24\% (22-26\%) in 2010 to $54 \%(50-58 \%)$ in 2015, reached a regional total of 10.3 million people. In South Africa, approximately 3.4 million people were on treatment, registering clients on ART with more than any other country in the world. Kenya has the largest treatment program in Africa, with nearly 900000 people on treatment at the end of 2015. Countries like Botswana, Eritrea, Kenya, Malawi, Mozambique, Rwanda, South Africa, Swaziland, Uganda, the United Republic of Tanzania, Zambia and Zimbabwe all increased treatment coverage by more than 25 percent between 2010 and 2015 (UNAIDS, 2016).

HIV/AIDS is the leading cause of mortality among women aged 15 - 49 in the world, and with several high burden countries like South Africa and Zimbabwe, leading to maternal mortality as a result of HIV. Although the rapid scale up of eMTCT services, countries are facing challenges in providing ARVs including the provision of antiretroviral treatment (ART) for HIV positive pregnant women and mother for treatment to reduce on paediatric infections, free HIV survival, and improved maternal and child health (WHO, 2010). Hence forth, $15 \%-30 \%$ babies become infected during gestation and delivery, and $5-15 \%$ become infected through breastfeeding. HIV infection of infants creates a life-long chronic condition that potentially shortens life expectancy. Primary prevention of HIV, prevention of unintended pregnancies, effective access to testing, counselling, antiretroviral therapy (ART), safe delivery practices, and appropriate infant feeding practices (including access to antiretroviral drugs to prevent HIV transmission to infants) all contribute to prevention of mother-to-child transmission (PMTCT) and also reduce child mortality.

In the past decade in sub Saharan Africa, many recommendations have been made to reduce the rate of mother to-child HIV infection. Therapeutic drugs were the most recommended preventive measure for HIV transmission. These recommendations played an important role in the reduction of mother to-child HIV transmission to a significant extent. However, some of the recommendations had major conflicts in regard to medication, follow up/retention, safety and efficacy of interventions, and the risk associated with such interventions. To stop the transmission of HIV from mother to her baby in Africa, the World Health Organization (WHO) promotes a comprehensive approach which includes primary prevention of HIV infection among women aged $15-49$ years old, preventing unwanted pregnancies among women living with HIV, Preventing HIV transmission from a woman living with HIV to her infant and providing appropriate treatment, care and support to mothers living with HIV and their children and families. This study will use the four approaches against which the researcher will examine the contribution of mother baby pair point approach in the reduction of eMTCT in the case of Arua district. Prevention is good but the WHO is looking beyond that and has also recommended the use of antiretroviral therapy (ART) as a potential means towards elimination and cure (Sidik, 2014).

Globally, HIV exposed infants (HEIs) have delayed access to early infant diagnosis of HIV (EID). Although new HIV infections have reduced, efforts towards "zero-new infections" and having 80\% HIV-infected infants started on antiretroviral therapy (ART) may be reversed if EID is delayed. According to the World Health Organization (WHO), three in every four HEIs have delayed access to EID services leading to high HIV-related childhood deaths in Sub-Saharan Africa despite the availability of antiretroviral therapy (ART). EID is hence a critical 
facilitator of early access to ART. In doing so, it ensures optimal viral suppression, reduced incidences of opportunistic infections, and improved quality of life of HIV-positive children (Izudi et al., 2016). Conversely, EID also has critical implications for infant survival. Previous studies suggested a 76\% reduced risk of infant mortality within the first 3 months of life, and 75\% reduced HIV progression to AIDS with early ART initiation. Given the aggressive course of pediatric HIV with an estimated $20 \%$ infant mortality before six months and $35-40 \%$ mortality before 12 months of age, the role of EID in early ART initiation cannot be underestimated (Izudi et al., 2016). Uganda is implementing Option-B plus that mandates initiation of ART in HIV-positive pregnant and lactating mothers irrespective of WHO clinical staging and immune status in order to eliminate mother to child transmission of HIV (eMTCT).

The international medical aid organization Medecins Sans Frontieres (MSF), in collaboration with the Ministry of Health, provides HIV/AIDS care in Arua, a rural region in northwestern Uganda. Arua district has a total population of about 785,189 according to the 2014 National Housing Census report and is near the borders of the Democratic Republic of Congo and South Sudan. MSF also treats HIVTB co-infection and supports 10 decentralized health Centre's in surrounding areas (Ahoua et al., 2009).

Arua regional referral hospital serves a predominantly rural community estimated at 785,189 inhabitants. The district of Arua has a high growth rate of $3.98 \%$. The population is predominantly peasantry with low socio-economic and health status. The human development and poverty indices in the northern region of Uganda including in the West Nile district of Arua are poor (Akello et al., 2008). The district health indices are poor with high under five mortality rate (U5MR) and infant mortality rate (IMR) of 240 and 100 per 1000 live births compared to the national figure of 152 and 88 respectively. However the district offers PMTCT or eMTCT services but the rate of loss to follow up is high and adherence is poor.

\subsection{Study Area}

Arua district lies between latitude $2030^{\prime} \mathrm{N}$ and $3050^{\prime} \mathrm{N}$ and longitude $30030^{\prime} \mathrm{E}$ and $31030^{\prime} \mathrm{E}$ in the north western part of Uganda. It is bordered by Yumbe in the North, Moyo district in the North east, Maracha district in the North West, Democratic Republic of Congo in the west, Nebbi and Zombo Districts in the south, and Amuru district in the east. Arua town, the Administrative and commercial Headquarters is 520 kilometres away from Kampala, Uganda's capital city. The district covers a Total area of 4274.13 Sq.km of which 87 percent of the land is arable.

The study was carried out in Arua Regional Referral Hospital, Adumi Health Center IV and Oli Health Center IV which are located in Arua Hill, Adumi and Oli sub-counties/divisions respectively. In this regard, the study considered cases of mother baby pair point approach to eMTCT outcomes in the District. Arua District has a population of 782,077 , the population is predominantly peasantry with low socio-economic and health status. The human development and poverty indices in the northern region of Uganda including in the West Nile district of Arua are appealing. The district health indices are poor with high under five mortality rate (U5MR) and infant mortality rate (IMR) of 240 and 100 per 1000 live births compared to the national figure of 152 and 88 respectively (Akello et al, 2008)

\subsection{Problem Statement}

Currently, HIV infection is incurable (Bhatta et al., 2015). However, an effective antiretroviral therapy (ART) can control the virus and help prevent or even eliminate the transmission of HIV from mother to child (Cohen et al., 2013). This risk of MTCT can be reduced by interventions that include prevention of unintended pregnancies among women of reproductive age, ARV prophylaxis given to women during pregnancy, labour and delivery and the infant in the first weeks of life. In the recent past, WHO advised HIV positive mothers to avoid breastfeeding if they were able to afford, prepare and store formula milk safely (Raga, 2010), with these interventions it is documented that new HIV infection among children have been reduced by $58 \%$ from 2000-2014 in the western world (Nguyen et al., 2016; UNAIDS, 2015).

One of the greatest challenges in preventing perinatal HIV transmission to babies in Utero is poor Antenatal care (ANC). It is therefore imperative to scale up ANC coverage to the large majority of HIV infected pregnant women to curtail the spread of the virus (Abrams et al., 2007). However, to what extent this can singly contribute to eMTCT outcomes is not known. Hence, this study seeks to establish contributions of mother baby care point approach to eMTCT outcome considering its ultimate goal HIV prevention as well as the processes involved. The study looked into both the supply side (the government's side, the health center) and the demand side (recipients of care). 
Arua district statistical abstract 2012 and HMIS 2010 indicates that 17,450 (46\%) clients were first time attendees of ANC as compared to 37,595 estimated population of pregnant women in the district. In addition to low number of first ANC attendance, the number of client for fourth ANC equally dropped to 7,748 which is equivalent to $21 \%$ of the expected 37,595 pregnant women. This fell far below the expected $50 \%$ of the national target. This greatly affects the fight to zero MTCT of HIV in infants because of loss to follow up and poor adherence to the treatment. Consequently, this leaves the mother - baby - pair point approach in jeopardy thus the need for this study.

\subsection{Broad Objective}

To establish the contribution of mother-baby-pair point approach to elimination of mother - to - child transmission (eMTCT) outcomes in Arua district

\subsection{Specific Objectives}

1) To determine the level of enrolment to eMTCT care of exposed infants in Arua district

2) To assess the contribution of Mother-Baby-Points toward eliminating mother to Child transmission of HIV in Arua district

3) To ascertain the maternal factors associated with retention on eMTCT care services by the exposed infant in Arua district

\section{Material and Methods}

\subsection{Study Design}

A descriptive and analytical cross sectional study design which employed both qualitative and quantitative methods (mixed methods approach) was used. The descriptive and qualitative aspects were most suited in getting descriptive and explanatory information based on three approaches; structured questionnaire, interview and focus group discussions.

\subsection{Study Population}

The study population comprised of HIV positive breastfeeding mothers, eMTCT focal person (Nurse in charge eMTCT), Nurses working in eMTCT clinic and NGOs/institutions offering eMTCT services

\subsection{Sample Size}

The sample size of respondents was based on a similar study on factors associated with the uptake of prevention of mother to child transmission services among women attending antenatal clinic at coast province general hospital (WHO, 2012)

Using a sample size formula by Kish Leslie;

$$
n=\frac{Z_{a}^{2} P(1-P)}{\delta^{2}}
$$

Where $\boldsymbol{n}=$ is the minimum sample size.

$\mathrm{P}=$ Population or prevalence known (0.85)

$\mathrm{q}=1-\mathrm{P}(1-0.85)=0.15$

$\mathrm{Z}_{\alpha}=$ Standard normal deviate at $95 \%$ confidence interval corresponding to 1.96

$\delta=$ is the degree of precision, which is $5 \%(0.05)$.

Thus; $n=\frac{[1.96 \times 1.96 \times 0.85(1-0.85)]}{[0.05 \times 0.05]}=\frac{0.489804}{0.0025}=195.9216$

$n=196$

\subsection{Sampling Techniques}

Purposive and simple random sampling technique was used to select the respondents. The researcher used purposive technique to select the key informants because these are people who are knowledgeable about the subject. They provided technical knowledge and input for the study. The mothers were randomly selected for the study in a way that each had equal chance of being selected. 


\subsection{Data Collection Tools and Procedures}

The data collection tools used includes Questionnaire, interviews and focus group discussions. Data collection procedures were as follows.

\subsubsection{Questionnaire}

Structured self-administered questionnaires were used. It was carried out in three health units selected as stated in section 1.2. The questions covered the demographic characteristics, socio economic indicators and other questions derived from the objectives of the study

\subsubsection{Interviews}

The researcher conducted key informant interviews with health workers in charge of eMTCT services in the three health facilities and nurses dealing with and engaged in the mother baby pair approach. Members of NGOs dealing with women engaged in eMTCT were also interviewed in order to gain perspective regarding the research objectives. The interview was unstructured and the study employed an interview guide as an instrument to guide the interviews

\subsubsection{Focus Group Discussions}

Three Focus group discussions were conducted with mothers who had HIV sero-positive babies. Although there was questionnaire for these women, the researcher used focus groups to get in-depth findings on issue pertaining to their babies and the women themselves. As matter of triangulation of methods and the importance of ensuring validity and reliability, the FGD helped to give more insight many issues and overcome bias opinion that questionnaires would have generated.

\subsection{Data Entry, Analysis and Presentation}

Data collected were entered in to statistical package for social scientists (SPSS) version 19, edited and cleansed. Analysis was done using SPSS and Microsoft excel, as appropriate. Univariate, bivariate and multivariate analysis as necessary, were run. Findings were presented as narratives and tables.

\subsection{Ethical Considerations}

Ethical approval was obtained from ethical committee of Uganda Martyrs University. This approval was presented to District Health Officer, Municipal Health Officer, Hospital Director of Arua Regional Referral Hospital, In-Charge Oli Health Centre IV and Adumi Health Centre IV. The purpose of the study, the entire procedure, the likely benefits and what is expected of the participants was clearly explained in a language understood by the community (Lugbara). Respondents were free to withdraw from the study without any penalty. Consent form highlighting participant voluntariness to participate in the study, was used as well as the willingness to sign consent form. All information given by participants was treated confidential and an assurance was made to that effect to the respondents.

\section{Results}

\subsection{Background Characteristics of Respondents}

The majority 136(69.4\%) of the respondents mothers were above the age of 25 years while few $60(30.6 \%)$ of the respondents were between 15-24 years of age. The majority 144(73.5\%) were living with their spouses in marital or cohabiting arrangements, few $42(21.4 \%)$ of the respondents were single and very few $10(5.1 \%)$ of the respondents were not living with their spouses due to being either divorced or widowed. The majority $145(74.1 \%)$ of the respondents were Christians, few 49(25\%) were Muslims and very few 2(1\%) belonged to other religious beliefs.

\subsection{Level of Enrolment on eMTCT Care}

The level of enrolment to care was assessed on a likert scale ranging from; 'immediately after delivery', 'within one week after delivery', 'within two weeks after delivery' to 'beyond two weeks after delivery'. See figure 1 below. 


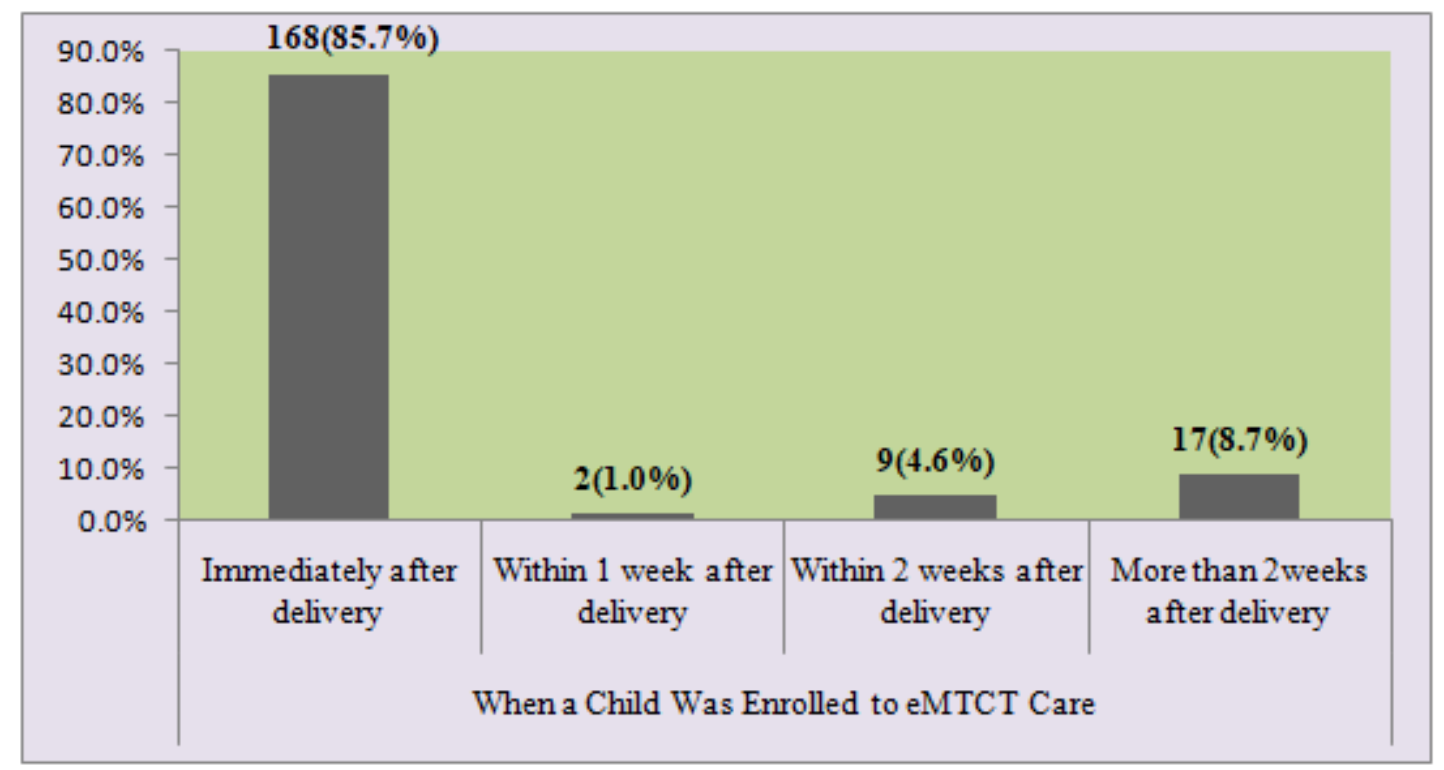

Figure 1. Levels of Enrolment to eMTCT Care

Majority $168(85.7 \%)$ of the respondents and their babies were enrolled to eMTCT care immediately after delivery, much as up to $17(8.7 \%)$ were enrolled beyond two weeks after delivery. Some of the reasons advanced by some respondents in regard to their enrolment into eMTCT care were; counseling before, during and after pregnancy on the importance of adherence to ART, early enrolment into care, and delivery in a health facility as per the verbatim below

"[...] when one was born with HIV since then I have been counseled...counseling before getting pregnant, before my second pregnancy is when I realized I have HIV, 7 months after delivery, after my third born". (Female 25 years old Oli HC IV)

"[...] some mothers do not attend ANC at all and others deliver at home. They come for treatment when they are sick and test in outpatient department routine counselling test". (KII 34 years old Arua RRH)

"[...] In some cases some mothers and babies are enrolled late during pregnancy labor and breast feeding." (KII 38 years old Adumi HCIV)

In focus groups when asked about what makes them to enroll for eMTCT services, one responded that it improves on quality of life

"[...] I enrolled for eMTCT services because I want to improve on the quality of my life since the ARVs will help me from getting other diseases and be able to do my work to earn a living" (Female 32 years old FGD ARRH)

Acceptance of HIV status

"[...] when I was pregnant I came for ANC and I was tested and found with HIV and I was counselled, talked to about the benefits of enrolling to eMTCT in order to deliver a HIV free baby" (Female 20 years old FGD Oli HCIV)

\subsection{Contribution of Mother-Baby-Points Toward Eliminating Mother to Child Transmission of HIV}

To determine the Contribution of Mother-Baby-Points toward Eliminating Mother to Child Transmission of HIV, the sero-status of the babies enrolled in different Mother-Baby-Points were ascertained. See Figure 2 below. 


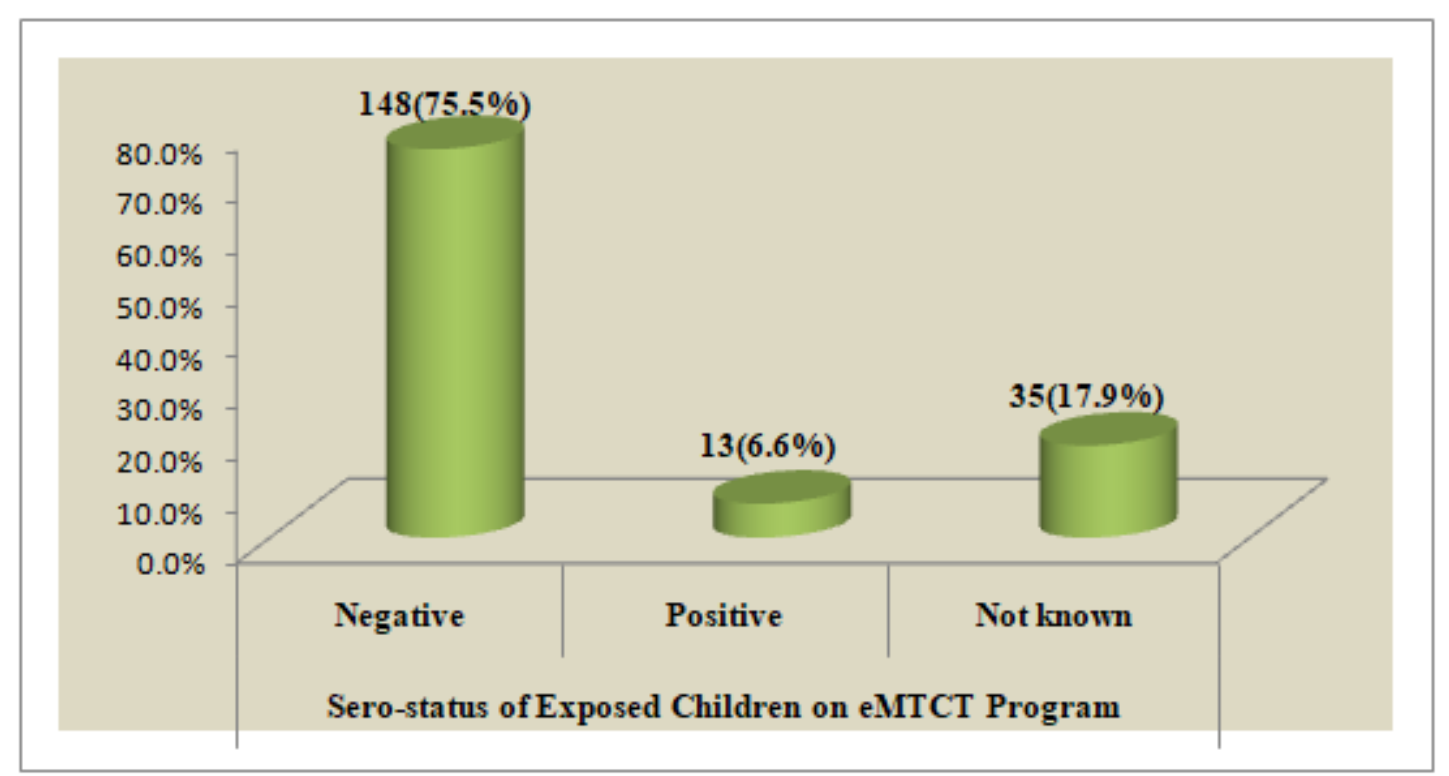

Figure 2. Contribution of Mother-Baby-Points toward eliminating mother to child transmission of HIV

The study found that most of the babies enrolled in mother-baby-points were HIV sero-negative (75.5\%) with only $6.6 \%$ of them being sero-positive, thus signifying the contribution of mother-baby-points towards eliminating mother-child-transmission of HIV. The $17.9 \%$ of unknown sero-status was because test results at the time of the interview were not yet out since most of the children here were below 6 weeks old.

Thus, the higher proportion sero-negative children could be highly attributable to the contribution of mother-baby-points towards eliminating mother-to-child transmission of HIV. This means that when strategies are consolidated and improved, the number of mother-to-child transmission can reduce to zero or near so.

In qualitative interview, mothers reported that they want to have HIV free babies and also want to live to bring up their children. Some of the reports are as follows;

\section{"[...] I want to have HIV free baby though I have the disease"- (Female 19 years old FGD Adumi HCIV) \\ "[...] I still need to live, I want to see my babies grow, study and I want to see them get employed so that they can stand on their own"- (Female 36 years old FGD Arua RRH)}

\subsection{Maternal Factors Associated With Retention on eMTCT Care Among Exposed Infants}

Bivariate analysis of maternal socio-demographic variable and retention on eMTCT care was done. Overall, retention on eMTCT care was at $172(87.8 \%)$, which is acceptably alright.

Table 1. Maternal factors associated with retention on eMTCT care among exposed infants

\begin{tabular}{|c|c|c|c|c|c|c|}
\hline \multirow{2}{*}{ Maternal Variables } & \multicolumn{2}{|c|}{ Retention on eMTCT Care } & \multirow{2}{*}{ Total } & \multicolumn{3}{|c|}{ Test Statistics } \\
\hline & Yes & No & & Df & $\chi^{2}$ Value & p-value \\
\hline \multicolumn{7}{|l|}{ 1. Age(in years) } \\
\hline - $15-19$ & $2(1.0 \%)$ & $2(1.0 \%)$ & 4 & & & \\
\hline - $\quad 20-24$ & $45(23.0 \%)$ & $11(5.6 \%)$ & 56 & & & \\
\hline $\begin{array}{l}-25-29 \\
-\quad 30-34\end{array}$ & $36(18.4 \%)$ & $3(1.5 \%)$ & 39 & 5 & 11.19 & $0.048 *$ \\
\hline $\begin{array}{l}50-34 \\
-\quad 35-39\end{array}$ & $57(29.1 \%)$ & $5(2.6 \%)$ & 62 & & & \\
\hline - 40 Above & $23(11.7 \%)$ & $3(1.5 \%)$ & 26 & & & \\
\hline & $9(4.6 \%)$ & $0(0.0 \%)$ & 9 & & & \\
\hline
\end{tabular}




\begin{tabular}{|c|c|c|c|c|c|c|}
\hline $\begin{aligned} \text { 2. } & \text { Marital status } \\
\text { : } & \text { Single } \\
\text { : } & \text { Darried } \\
\text { : } & \text { Widoweded } \\
\text { - } & \text { Cohabiting }\end{aligned}$ & $\begin{array}{l}38(19.4 \%) \\
118(60.2 \%) \\
5(2.6 \%) \\
2(1.0 \%) \\
9(4.6 \%)\end{array}$ & $\begin{array}{l}4(2.0 \%) \\
17(8.7 \%) \\
3(1.5 \%) \\
0(0.0 \%) \\
0(0.0 \%)\end{array}$ & $\begin{array}{l}42 \\
135 \\
8 \\
2 \\
9\end{array}$ & 4 & 6.588 & 0.159 \\
\hline $\begin{array}{l}\text { 3. Religion } \\
\begin{aligned} \text { : } & \text { Catholics } \\
\text { : } & \text { Protestants } \\
\text { : } & \text { Muslims } \\
\text { : } & \text { Pentecostals } \\
\text { - } & \text { Others }\end{aligned}\end{array}$ & $\begin{array}{l}80(40.8 \%) \\
43(21.9 \%) \\
44(22.4 \%) \\
3(1.5 \%) \\
2(1.0 \%)\end{array}$ & $\begin{array}{l}5(2.6 \%) \\
12(6.1 \%) \\
5(2.6 \%) \\
2(1.0 \%) \\
0(0.0 \%)\end{array}$ & $\begin{array}{l}85 \\
55 \\
49 \\
5 \\
2\end{array}$ & 4 & 11.947 & 0.018* \\
\hline $\begin{array}{l}\text { 4. Having had any form of } \\
\text { education on eMTCT } \\
\begin{array}{l}\text { - Yes } \\
\text { - No }\end{array}\end{array}$ & $\begin{array}{l}136(69.4 \%) \\
36(18.4 \%)\end{array}$ & $\begin{array}{l}22(11.2 \%) \\
2(1.0 \%)\end{array}$ & $\begin{array}{l}158 \\
38\end{array}$ & 1 & 2.133 & 0.001* \\
\hline $\begin{aligned} \text { 5. Education level } \\
\begin{aligned} \text { - } & \text { Primary } \\
\text { : } & \text { Secondary } \\
\text { - } & \text { Tecational Training } \\
& \text { Tertiary /University }\end{aligned}\end{aligned}$ & $\begin{array}{l}68(34.7 \%) \\
55(28.1 \%) \\
9(4.6 \%) \\
4(2.0 \%)\end{array}$ & $\begin{array}{l}17(8.7 \%) \\
5(2.6 \%) \\
0(0.0 \%) \\
0(0.0 \%)\end{array}$ & $\begin{array}{l}85 \\
60 \\
9 \\
4\end{array}$ & 3 & 6.286 & 0.099 \\
\hline $\begin{array}{l}\text { 6. Occupation of Husband } \\
\begin{aligned} & \text { - } \text { Formal employment } \\
& \text { - } \text { Petty Business } \\
& \text { - } \text { Peasant } \\
& \text { Others }\end{aligned}\end{array}$ & $\begin{array}{l}54(27.6 \%) \\
35(17.9 \%) \\
27(13.8 \%) \\
56(28.6 \%)\end{array}$ & $\begin{array}{l}6(3.1 \%) \\
11(5.6 \%) \\
3(1.5 \%) \\
4(2.0 \%)\end{array}$ & $\begin{array}{l}60 \\
46 \\
30 \\
60\end{array}$ & 3 & 7.988 & $0.046 *$ \\
\hline
\end{tabular}

Df $=$ Degree of freedom, $\chi^{2}=$ Chi Square, $*=$ Significant results

The study found that age of the mothers was associated with retention on eMTCT care $\left(\chi_{(5)}^{2}=11.19, \boldsymbol{p}=\mathbf{0 . 0 4 8}\right.$ ). Fewer of the younger mothers below 20years (1.0\%) and fewer of the older mothers above 40years (4.6\%) were retained on EMTCT care.

Results showed that out of those who were Catholics majority 80 (94.1\%) were consistent in attending eMTCT services. Chi-square results indicated that there is significant relationship between religion and retention on eMTCT services $\left(\chi_{(4)}^{2}=11.947, \boldsymbol{p}=\mathbf{0 . 0 1 8}\right)$.

Having had any form of education on eMTCT was associated with retention on eMTCT care $\left(\chi_{(1)}^{2}=2.133\right.$, $\boldsymbol{p}=\mathbf{0 . 0 0 1}$ ). Most of the respondents 136(69.4\%) who had some form of education on eMTCT were retained on care. Occupation of husbands was also found to be associated with retention on eMTCT care $(\boldsymbol{p}=\mathbf{0 . 0 4 6})$.

\section{Discussions}

In this study, the majority of the respondents were enrolled to eMTCT services, this was revealed in the response that show $91.8 \%$ respondents enrolled when pregnant with the infant, while $85.7 \%$ were enrolled to Nevirapine syrup immediately after delivery. This implies that many people still do not attend ANC while pregnant and some still deliver from home, hence hindering enrollment to care of these exposed infants. This is in line with the finding by Ahemd et al (2015) which recognized that early mother, infant enrollment and diagnosis plays an important role in eliminating vertical transmission of HIV, reducing morbidity and mortality.

This study found that age of the mothers was associated with retention on eMTCT care $(\boldsymbol{p}=\mathbf{0 . 0 4 8})$. In support, Musarandega et al. (2017) showed that a number of studies have found that young people were less likely to take an HIV test and that those who are HIV infected have poorer HIV treatment uptake, retention and outcomes. 
The study revealed that having had some form of education on eMTCT was associated with retention on care. Health facilities have been quite successful in increasing knowledge about eMTCT services and have been the first source of knowledge about eMTCT services. This is in agreement with (Katushabe as cited in Tayali, 2015) which found out that hospital health education was the most frequently stated channel through which women get information regarding mother to child transmission and eMTCT services.

The majority of respondents reported that they have been consistent in attending eMTCT services. This could be as a result of the zeal to fight for the safety of their unborn or breast feeding infants and to leave a healthy life with $75 \%$ being consistent over one year and above. The findings are also in line with Hassan et al. (2012) as cited in Adeniyi et al (2015) whose study showed that three-quarter of mothers give up on care before six months after delivery with about $85 \%$ by the twelfth month of follow up in South Africa.

\section{Conclusions}

The study concludes that, although the level of enrollment in to eMTCT care is found to be high, there are some mothers who still enroll late, thus, affecting early infant diagnosis, uptake of eMTCT services and retention of mothers and their infants. In many instances, Stigma, long distance to health facility and denial were found to significantly affect retention in care of eMTCT mothers at baby care points. A paradigm shift is needed by ministry of health to strengthen community health systems by mobilizing a broad cross-section of community groups (such as Agricultural groups, religious groups, sports, education, credit and savings groups) to support uptake and retention of eMTCT.

\section{Acknowledgments}

We acknowledge support of faculty of health sciences staff of Uganda Martyrs University. The authors also acknowledge in a special way, Mr Anguyo Robert, for his support in this study. Special appreciations go to Arua District local Government, most especially; District health office, Arua Municipal health office, Arua Regional Referral hospital, Oli Health Centre IV, Adumi health Centre IV and all our dear respondents, without whom this study wouldn't have been a success.

\section{References}

Abdul-Mumuni, S. (2014). Prevention of HIV Mother-To-Child-Transmission in sub-Saharan Africa.

Abrams, E. J., Myer, L., Rosenfield, A., \& El-Sadr, W. M. (2007). Prevention of mother-to-child transmission services as a gateway to family-based human immunodeficiency virus care and treatment in resource-limited settings: rationale and international experiences. American Journal of Obstetrics and Gynecology, 197(3), S101-S106. https://doi.org/10.1016/j.ajog.2007.03.068

Adeniyi, V. O., Thomson, E., Ter Goon, D., \& Ajayi, I. A. (2015). Disclosure, stigma of HIV positive child and access to early infant diagnosis in the rural communities of OR Tambo District, South Africa: a qualitative $\begin{array}{llllll}\text { exploration of maternal perspective. } & \text { BMC }\end{array}$ https://doi.org/10.1186/s12887-015-0414-8.

Ahmed, S., Kim, M. H., Dave, A. C., Sabelli, R., Kanjelo, K., Preidis, G. A., ... Chimbwandira, F. (2015). Improved identification and enrolment into care of HIV-exposed and-infected infants and children following a community health worker intervention in Lilongwe, Malawi. Journal of the International AIDS Society, 18(1). https://doi.org/10.7448/IAS.18.1.19305

Ahoua, L., Ayikoru, H., Gnauck, K., Odaru, G., Odar, E., Ondoa-Onama, C., ... Pujades-Rodríguez, M. (2010). Evaluation of a 5-year programme to prevent mother-to-child transmission of HIV infection in Northern Uganda. Journal of Tropical Pediatrics, 56(1), 43-52. Retrieved from http://hdl.handle.net/10144/12033210.1093/tropej/fmp054

Akello, B., Nabiwemba, E., Zirabamuzaale, C., \& Orach, C. G. (2008). Risk factors for perinatal mortality in Arua regional referral hospital, west Nile, Uganda. East African Journal of Public Health, 5(3). https://doi.org/10.4314/eajph.v5i3.39000

Alan, B. (2012). Social Research Methods (4th ed.). New Delhi: Oxford University Press.

Alonso-González, M. (2010). Regional Initiative for the Elimination of Mother-to-Child Transmission of HIV and Congenital Syphilis in Latin America and the Caribbean: regional monitoring strategy.

Bhatta, D. N., Aryal, U. R., \& Khanal, K. (2015). Education: the key to curb HIV and AIDS epidemic. Kathmandu University Medical Journal, 11(2), 158-161. https://doi.org/10.3126/kumj.v11i2.12493 
Cohen, M. S., Smith, M. K., Muessig, K. E., Hallett, T. B., Powers, K. A., \& Kashuba, A. D. (2013). Antiretroviral treatment of HIV-1 prevents transmission of HIV-1: where do we go from here?. The Lancet, 382(9903), 1515-1524. https://doi.org/10.1016/S0140-6736(13)61998-4

Dabis, F., Leroy, V., Castetbon, K., Spira, R., Newell, M. L., \& Salamon, R. (2000). Preventing mother-to-child transmission of HIV-1 in Africa in the year 2000. Aids, 14(8), 1017-1026. https://doi.org/10.1097/00002030-200005260-00014

Izudi, J., Akot, A., Kisitu, G. P., Amuge, P., \& Kekitiinwa, A. (2016). Quality Improvement Interventions for Early HIV Infant Diagnosis in Northeastern Uganda. https://doi.org/10.1155/2016/5625364

MUCHEMI, C. W. (2014). Department of Sociology and Social Work. Doctoral dissertation, University of Nairobi.

Musarandega, R., Machekano, R., Chideme, M., Muchuchuti, C., Mushavi, A., Mahomva, A., \& Guay, L. (2017). PMTCT service uptake among adolescents and adult women attending antenatal care in selected health facilities in Zimbabwe. Journal of Acquired Immune Deficiency Syndromes, 75(2), 148.

Chia, A., Nguyen, A., \& Ocran, S. (2016). Prevention of mother to child HIV transmission in resource-limited areas: a literature review. Retrieved from https://www.theseus.fi/handle/10024/112369

Raqa, T. (2010). Breast is always best, even for HIV-positive mothers. Bull World Health Organ, 88, 9-10. https://doi.org/10.2471/BLT.10.030110

Tayali, S. (n.d). HIV prevention of mother to child transmission communication strategies: A case study of Chelstone Township in Lusaka. Doctoral dissertation.

UNAIDS. (2016). Global AIDs update; Retrieved June 7, 2017, from www.unaids.org/sites/default/files/media_asset/global-AIDS-update-2016_en.pdf

World Health Organization. (2014). Global guidance on criteria and processes for validation: elimination of mother-to-child transmission (eMTCT) of HIV and syphilis, Geneva: WHO.

World Health Organization. (2010). PMTCT strategic vision 2010-2015: Preventing mother-to-child transmission of HIV to reach the UNGASS and Millennium Development Goals: moving towards the elimination of paediatric HIV, Geneva: WHO.

\section{Copyrights}

Copyright for this article is retained by the author(s), with first publication rights granted to the journal.

This is an open-access article distributed under the terms and conditions of the Creative Commons Attribution license (http://creativecommons.org/licenses/by/4.0/). 